Check for updates

Cite this: Chem. Sci., 2019, 10, 1735

๑ All publication charges for this article have been paid for by the Royal Society of Chemistry

\title{
Chemical CD oscillation and chemical resonance phenomena in a competitive self-catalytic reaction system: a single temperature oscillation induces CD oscillations twice $\dagger$
}

\author{
Tsukasa Sawato, Yasuhiro Shinozaki, Nozomi Saito and Masahiko Yamaguchi (D) *
}

Chemical CD oscillation and chemical resonance phenomena appear in a competitive chemical reaction system involving amplification. A pseudoenantiomeric mixture of an aminomethylenehelicene $(P)$ tetramer and an (M)-hexamer in toluene forms three states, namely hetero-double-helix B, heterodouble-helix $\mathrm{C}$, and dissociated random-coil $2 \mathrm{~A}$. When the temperature of the solution is oscillated between -5 and $38{ }^{\circ} \mathrm{C}$ at a rate of $2 \mathrm{~K} \mathrm{~min}^{-1}, \Delta \varepsilon$ reaches maxima twice during a single temperature oscillation, which is called a chemical $C D$ oscillation phenomenon. The phenomenon arises from the sharp competition between the two self-catalytic $2 \mathrm{~A}+\mathrm{C}$-to-2C and $2 \mathrm{~A}+\mathrm{B}$-to-2B reactions. In addition, the chemical $C D$ oscillation appears, when temperature oscillation occurs at a rate of $2 \mathrm{~K} \mathrm{~min}^{-1}$, and higher and lower rates provide a single maximum, a process referred to as the chemical resonance phenomenon. The changes in concentration induced by temperature oscillation repeatedly crossed equilibrium.

Received 13th July 2018

Accepted 29th November 2018

DOI: $10.1039 / \mathrm{c} 8 \mathrm{sc} 03109 f$

rsc.li/chemical-science

\section{Introduction}

A chemical reaction is generally conducted under constant temperature (isothermal) conditions. It is not common to introduce temperature changes during a chemical reaction..$^{1-3}$ Oscillation is an interesting phenomenon in nature, in which the strength or direction of a process regularly changes, ${ }^{4,5}$ and introducing temperature oscillation during a chemical reaction can result in interesting phenomena..$^{6-10}$ Such studies, however, have not been conducted in a systematic manner. When temperature oscillation is introduced in an irreversible chemical reaction, the reaction rate changes in accordance with the rate constant $k=A \exp \left(-E_{\mathrm{a}} / R T\right)$ according to chemical kinetics, in which $A, E_{\mathrm{a}}, R$, and $T$ are the frequency factor, activation energy, gas constant, and absolute temperature, respectively. Temperature oscillation both increases and decreases $k$, and the reaction rate increases on heating and decreases on cooling, during which the reaction proceeds in the same direction. The effect of temperature oscillation on an irreversible chemical reaction is relatively small.

Temperature oscillation can also be considered for a chemical equilibrium, which is a reversible chemical reaction. The

Department of Organic Chemistry, Graduate School of Pharmaceutical Sciences, Tohoku University, Aoba, Sendai 980-8578, Japan. E-mail: yama@m.tohoku.ac.jp; Fax: +81-22-795-6811

$\dagger$ Electronic supplementary information (ESI) available: Full experimental details including general methods, CD, UV-vis, and DLS analyses. See DOI: $10.1039 / \mathrm{c} 8 \mathrm{sc} 03109 \mathrm{f}$ reaction can proceed in forward and backward directions depending on the temperature. The effect of temperature oscillation is expressed by the change in the equilibrium constant $K=\exp (-\Delta G / R T)$, in which $\Delta G$ is the free energy difference between substrates and products. Temperature oscillation induces $K$ oscillation, in which the ratio of the forward to backward reaction rate oscillates. Because $K$ is unique for a single temperature, the same curve is obtained in concentration/temperature profiles for heating and cooling,

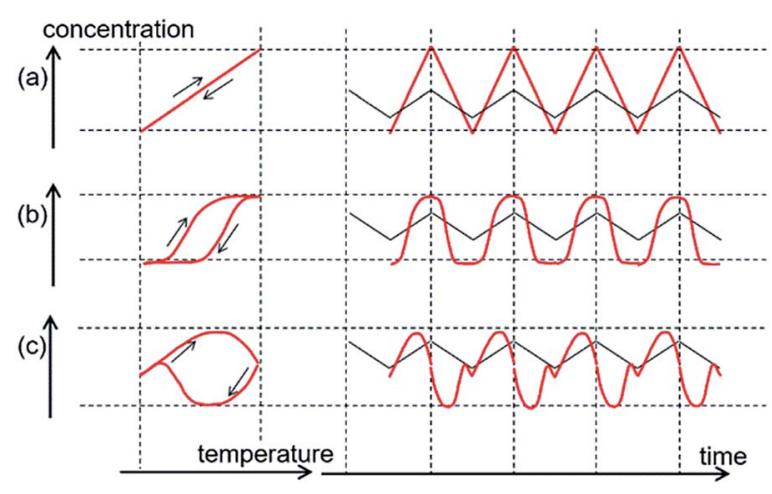

Fig. 1 Schematic representation of chemical reactions in response to temperature oscillation as shown by time/concentration and temperature/concentration profiles (a) at chemical equilibrium, (b) with thermal hysteresis, and (c) for a chemical CD oscillation response. Black lines indicate input and red lines indicate output in time/ concentration profiles. 
and concentration changes synchronize with temperature oscillation as shown in concentration/time profiles (Fig. 1a). The chemical reaction rate in response to temperature oscillation is very fast in such systems compared with the rate of temperature oscillation.

When the chemical reaction rate in response to temperature oscillation is lower than the rate of temperature oscillation, time delay phenomena appear. Temperature/concentration profiles exhibit thermal hysteresis, in which cooling and heating result in different curves (Fig. 1b). Nonlinear phenomena can appear, as shown in temperature/time profiles.

Complexity is enhanced when a competitive amplification reaction system is subjected to temperature oscillation. In this study, we describe such a phenomenon, in which a single temperature oscillation provides two concentration maxima, as shown in concentration/time profiles by CD (circular dichroism spectroscopy) (Fig. 1c). The phenomenon results from competition between two self-catalytic reactions that provide different products, for which time delay responses are amplified. This can be regarded as the chemical CD oscillation of temperature oscillation to concentration oscillation, and a single temperature oscillation input is converted into a CD oscillation output twice by a chemical reaction. In addition, the chemical resonance phenomenon arises, in which the temperature oscillation rate plays a critical role in the chemical CD oscillation. It should be noted that these phenomena are caused by molecules dispersed in solution without forming higher aggregates. ${ }^{\mathbf{1 1 , 1 2}}$ Chemical oscillations such as the Belousov-Zhabotinsky reaction under isothermal conditions have been known, ${ }^{13-16}$ and the present phenomena describe concentration oscillation in response to temperature oscillation.

We previously reported that a pseudoenantiomeric mixture of aminomethylenehelicene $(P)$-tetramer $(P)$-1 and $(M)$-pentamer (M)-2 (Fig. 2b) in dilute solution exhibited three-state structural changes between random-coil 2A, hetero-doublehelix B, and hetero-double-helix $\mathbf{C .}^{\mathbf{1 7 - 2 0}} \mathbf{B}$ and $\mathbf{C}$ are enantiomeric with regard to the three-dimensional structures of righthanded and left-handed helices, and $\mathbf{B}$ shows a negative
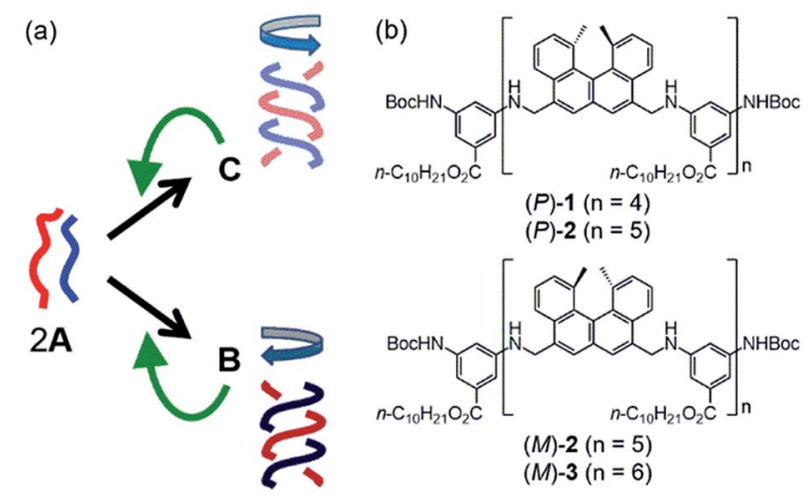

Fig. 2 (a) Competition between self-catalytic $2 \mathrm{~A}+\mathrm{C}$-to-2C and $2 \mathrm{~A}+$ $\mathrm{B}$-to-2B reactions in a 1:1 mixture of pseudoenantiomeric aminomethylenehelicene $(P)$-oligomer and $(M)$-oligomer. Green arrows indicate self-catalytic amplification. (b) Chemical structures of aminomethylenehelicene oligomers.
Cotton effect at $315 \mathrm{~nm}$ and $\mathbf{C}$ a positive one in CD (Fig. 2a). The thermodynamic stability of the $(M)-\mathbf{1} /(P)-\mathbf{2}$ system reverses in response to temperature change: at high temperatures, a solution of $\mathbf{2 A}$ is thermodynamically the most stable; at low temperatures, a solution of $\mathbf{C}$ is the most stable. Then, $\mathbf{B}$ solution is metastable. The $(M)-\mathbf{1} /(P)-\mathbf{2}$ system exhibited unusual chemical phenomena such as molecular thermal hysteresis, ${ }^{\mathbf{1 7}}$ chiral symmetry breaking, ${ }^{18}$ a homogeneous-heterogeneous transition, ${ }^{19}$ and shortcut pathways, ${ }^{20}$ which were derived from the competition between the self-catalytic $2 \mathbf{A}+\mathbf{B}$-to- $2 \mathbf{B}$ and $2 \mathbf{A}+$ $\mathbf{C}$-to-2 $\mathbf{C}$ reactions that provided different products $\mathbf{B}$ and $\mathbf{C}$ in an amplified manner, respectively (Fig. 2a). This study shows chemical CD oscillation and chemical resonance phenomena in a mixture of $(P)$-1 and $(M)$-hexamer $(M)$-3, which did not appear in the previously studied $(M)-\mathbf{1} /(P)-2$ system. The notable phenomena of the $(P)-\mathbf{1} /(M)-\mathbf{3}$ system were ascribed to the competition between self-catalytic reactions with different sensitivities.

\section{Results and discussion}

\section{Determination of hetero-double-helix formation}

It was initially confirmed that the $(P)-\mathbf{1} /(M)-\mathbf{3}$ system exhibited three-state structural changes between random-coil $2 \mathbf{A}$, hetero-double-helix B, and hetero-double-helix C. A 1:1 mixture of $(P)-1$ and $(M)-3$ (total $0.25 \mathrm{mM}$ ) in toluene at $70{ }^{\circ} \mathrm{C}$ was in the dissociated state $2 \mathbf{A}$, which produced a weak Cotton effect (Fig. S1a $\dagger$ ). Cooling the solutions to $5{ }^{\circ} \mathrm{C}$ caused a negative Cotton effect to appear at $315 \mathrm{~nm}$. UV-vis showed a decrease in intensity and a shift of the absorption maximum from $295 \mathrm{~nm}$ to $305 \mathrm{~nm}$ (Fig. S1b†). These results are consistent with hetero-double-helix B formation. The solution was allowed to settle at room temperature for 4 days, during which time the Cotton effect at $315 \mathrm{~nm}$ was reversed from negative to positive, indicating an enantiomeric structure associated with the formation of $\mathbf{C}$. Dynamic light scattering (DLS) experiments indicated average diameters of $0.62 \mathrm{~nm}$ for random-coil $\mathrm{A}$ and $8.7 \mathrm{~nm}$ for hetero-double-helix C (Fig. S2 $\dagger$ ). These experimental results from the $(P)-\mathbf{1} /(M)-\mathbf{3}$ system were consistent with those from the previously studied $(M)-1 /(P)-2$ system, which indicates that such a structure change is caused by dispersed molecules in solution without forming higher aggregates. ${ }^{17}$

The equilibrium-shifted S-states for $\mathbf{B}$ and $\mathbf{C}$ in fluorobenzene, a solvent that promotes aggregate formation, were also determined (Fig. S3†). ${ }^{17}$ A fluorobenzene solution of $(P)-\mathbf{1} /$ $(M)$-3 (total $0.5 \mathrm{mM}$ ) was heated to $70{ }^{\circ} \mathrm{C}$ and then cooled to $20{ }^{\circ} \mathrm{C}$ to provide a solution of $\mathbf{B}$. This $\mathbf{B}$ solution was allowed to settle for 3 days, during which time it converted to a solution of C. The same experiment was conducted at a higher concentration of $1.0 \mathrm{mM}$, and identical CD and UV-vis spectra were obtained at 0.5 and $1.0 \mathrm{mM}$ for both $\mathbf{B}$ and $\mathbf{C}$. The solutions were determined to be in the equilibrium-shifted S-states, not containing other species, with the $\Delta \varepsilon(315 \mathrm{~nm})$ values of $-359 \mathrm{~cm}^{-1}$ $\mathbf{M}^{-1}$ for $\mathbf{B}$ and $+280 \mathrm{~cm}^{-1} \mathbf{M}^{-1}$ for $\mathbf{C}$. As previously noted in the $(M)-\mathbf{1} /(P)-2$ system, ${ }^{17} \mathbf{B}$ and $\mathbf{C}$ in the S-states showed enantiomeric CD spectra. 


\section{Thermal hysteresis experiment}

A complex structural change was observed for the $(P)-\mathbf{1} /(M)-\mathbf{3}$ system in experiments upon cooling and heating at constant rates in toluene, which was not previously observed in the $(P)-\mathbf{1} /$ $(M)$-2 system. A 1 : 1 mixture of $(P)-1$ and $(M)$-3 (total $0.25 \mathrm{mM}$ ) in toluene at $90{ }^{\circ} \mathrm{C}$ consisted of dissociated $2 \mathrm{~A}$. The solution was cooled to $-5{ }^{\circ} \mathrm{C}$ at a rate of $2.0 \mathrm{~K} \mathrm{~min}^{-1}$ and then heated to $90{ }^{\circ} \mathrm{C}$. The process was monitored by observing $\Delta \varepsilon$ at $315 \mathrm{~nm}$ in $\mathrm{CD}$ and $\varepsilon$ at $315 \mathrm{~nm}$ in UV-vis (Fig. 3, red lines). Upon cooling, $\Delta \varepsilon$ monotonically decreased to $-42 \mathrm{~cm}^{-1} \mathrm{M}^{-1}$ at $-5{ }^{\circ} \mathrm{C}$. Upon heating, $\Delta \varepsilon$ decreased to $-124 \mathrm{~cm}^{-1} \mathrm{M}^{-1}$ at $20^{\circ} \mathrm{C}$, which indicated the formation of $\mathbf{B}$ (Fig. 3a). Above $20{ }^{\circ} \mathrm{C}, \Delta \varepsilon$ increased, reached $-25 \mathrm{~cm}^{-1} \mathrm{M}^{-1}$ at $35{ }^{\circ} \mathrm{C}$, and then decreased slightly at $40{ }^{\circ} \mathrm{C}$. Further heating increased $\Delta \varepsilon$, and produced dissociated $2 \mathbf{A}$ at $60{ }^{\circ} \mathrm{C}$. It was noted that heating of a solution of $\mathbf{B}$ did not monotonically provide $2 \mathbf{A}$, and an upward inflation appeared at $35{ }^{\circ} \mathrm{C}$ in $\Delta \varepsilon(315 \mathrm{~nm}) /$ temperature profiles. Such a phenomenon was observed at $0.2 \mathrm{mM}$ but not at 0.1 or $0.5 \mathrm{mM}$ (Fig. S4 $\dagger$ ). The thermal hysteresis of the $(P)-\mathbf{1} /(M)-\mathbf{3}$ system is different in shape from those of $(P)-1 /(M)-2$ and $(P)-2 /(M)-3$ systems (Fig. S5 $\dagger) .{ }^{17}$

The upward inflation of $\Delta \varepsilon$ in the $(P)-\mathbf{1} /(M)-\mathbf{3}$ system in toluene (total $0.25 \mathrm{mM}$ ) also appeared at the temperature change rates of 1.0 and $5.0 \mathrm{~K} \mathrm{~min}^{-1}$, but was enhanced at slower temperature change rates (Fig. 3a). Correspondingly, at a very low temperature change rate of $0.1 \mathrm{~K} \mathrm{~min}^{-1}$, a significant upward inflation was observed (Fig. S6 $\dagger$ ). In an experiment with cooling to $-10{ }^{\circ} \mathrm{C}$ instead of $-5{ }^{\circ} \mathrm{C}$, a slight upward inflation appeared (Fig. $\mathrm{S} 7 \dagger$ ).

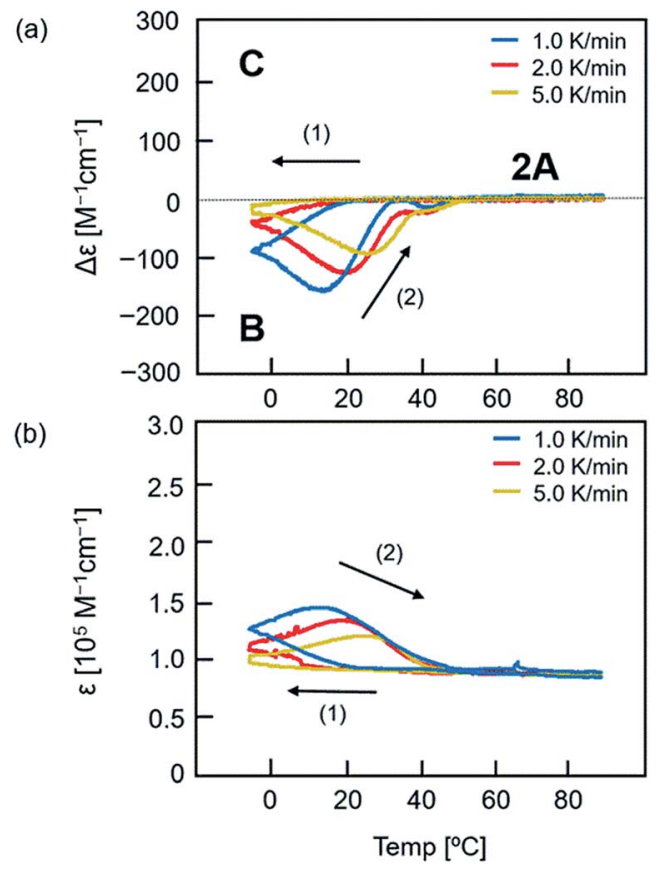

Fig. 3 Thermal hysteresis of $(P)-1 /(M)-3(1: 1)$ in toluene (total 0.25 $\mathrm{mM}$ ) at heating/cooling rates of $1.0 \mathrm{~K} \mathrm{~min}^{-1}$ (blue line), $2.0 \mathrm{~K} \mathrm{~min}^{-1}$ (red line), and $5.0 \mathrm{~K} \mathrm{~min}^{-1}$ (yellow line). The temperature decreased from $90{ }^{\circ} \mathrm{C}$ to $-5^{\circ} \mathrm{C}$, and then increased to $90^{\circ} \mathrm{C}$. The results are shown in (a) $\Delta \varepsilon(315 \mathrm{~nm}) /$ temperature profiles and (b) $\varepsilon(315 \mathrm{~nm}) /$ temperature profiles.

\section{Temperature oscillation experiment}

When the temperature was oscillated, the upward inflations were amplified and occurred twice during a single cycle (Fig. 4). A solution of dissociated $2 \mathrm{~A}$ (total $0.25 \mathrm{mM}$ ) of $(P)-1 /(M)-3$ at $70{ }^{\circ} \mathrm{C}$ was cooled to $-5{ }^{\circ} \mathrm{C}$ at a rate of $2.0 \mathrm{~K} \mathrm{~min}^{-1}$, and the temperature was oscillated between $38{ }^{\circ} \mathrm{C}$ and $-5{ }^{\circ} \mathrm{C}$ at a rate of $2.0 \mathrm{~K} \mathrm{~min}^{-1}$. Different cooling and heating curves were obtained depending on the number of temperature oscillation cycles as shown in the $\Delta \varepsilon(315 \mathrm{~nm}) /$ temperature profiles, and $\Delta \varepsilon$ gradually increased with cycles (Fig. 4a). Downward inflations at 20$30{ }^{\circ} \mathrm{C}$ appeared in the initial cooling and two upward inflations at approximately 30 and $0{ }^{\circ} \mathrm{C}$ in the third and later heating cycles. It was determined that $\mathbf{B}$ and $\mathbf{C}$ in the S-states showed enantiomeric CD spectra with essentially identical intensities (Fig. S3 $\dagger$ ). Then, the increase in $\Delta \varepsilon$ with repeated cycles is due to the increase in the concentration of $\mathbf{C}$ and decrease in that of $\mathbf{B}$, which is consistent with $\mathbf{C}$ being thermodynamically more stable than B (Fig. S1 and S3†). The nonlinear properties of the thermal response became clear when the fourth temperature oscillation cycle was extracted (Fig. 4b). During a single heating and cooling cycle, $\Delta \varepsilon$ increased twice at 30 and $5{ }^{\circ} \mathrm{C}$ and decreased once at $23{ }^{\circ} \mathrm{C}$. It should also be noted that the equilibrium curve, which will be described later, was significantly and repeatedly crossed during temperature oscillation (Fig. 4a and b). ${ }^{21}$

UV-vis analysis provided $\varepsilon(315 \mathrm{~nm}) /$ temperature profiles, in which heating and cooling curves converged with repeated cycles (Fig. S11b $\dagger$ ). It was determined that $\mathbf{B}$ and $\mathbf{C}$ gave essentially identical UV-vis spectra in the S-state (Fig. S3 $\dagger$ ). These results indicate that the oscillation of $\Delta \varepsilon$ is derived from the oscillation of the ratio of $[\mathbf{B}]$ and $[\mathbf{C}]$.

The $\Delta \varepsilon$ /temperature profiles were converted to $\Delta \varepsilon /$ time profiles, which confirmed that the oscillation of $\Delta \varepsilon$ was induced by the temperature oscillation (Fig. $4 \mathrm{c}$ and $\mathrm{S} 8 \dagger$ ). Two initial heating and cooling cycles showed downward inflation of $\Delta \varepsilon$, which switched to upward inflation in the third and later cycles. In addition, two $\Delta \varepsilon$ maxima appeared in the third and later cycles in response to a single temperature oscillation between -5 and $38{ }^{\circ} \mathrm{C}$. Expansion of the fourth cycle showed two $\Delta \varepsilon$ maxima, 1 and 2 (Fig. 4d). Such a chemical CD oscillation phenomenon is unprecedented in a chemical reaction.

\section{Effect of the temperature change rate in temperature oscillation}

The effect of temperature oscillation rate was examined between -5 and $38{ }^{\circ} \mathrm{C}$ (Fig. $5 \mathrm{a}$ and $\mathrm{S} 10-\mathrm{S} 13 \dagger$ ). At the higher rates of 3.0 and $4.0 \mathrm{~K} \mathrm{~min}^{-1}$, a damped oscillation of $\Delta \varepsilon$ occurred approaching $\Delta \varepsilon 0 \mathrm{~cm}^{-1} \mathrm{M}^{-1}$, in which a downward oscillation of $\Delta \varepsilon$ continuously occurred during heating. At a lower rate of 1.0 $\mathrm{K} \min ^{-1}$, downward oscillation occurred in the initial cycles during heating, which switched to an upward oscillation during cooling. At 1.0, 3.0, and $4.0 \mathrm{~K} \mathrm{~min}^{-1}$, a single heating and cooling cycle provided a single oscillation of $\Delta \varepsilon$. The chemical CD oscillation was observed at $2.0 \mathrm{~K} \mathrm{~min}^{-1}$, in which a single heating and cooling cycle provided two $\Delta \varepsilon$ maxima. This can be regarded as a chemical resonance phenomenon, in which 
(a)

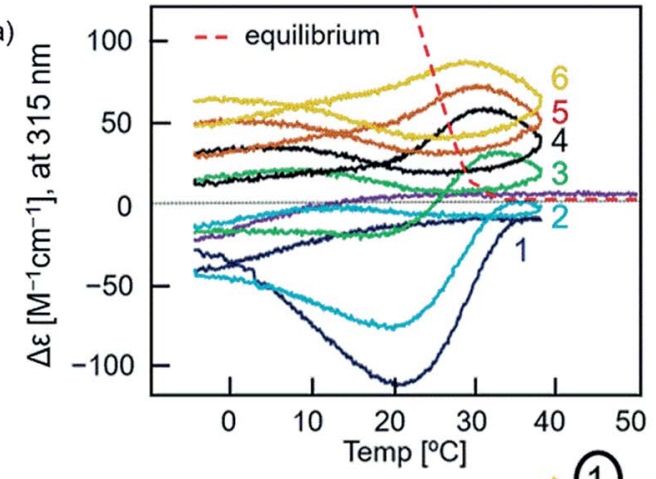

(b)

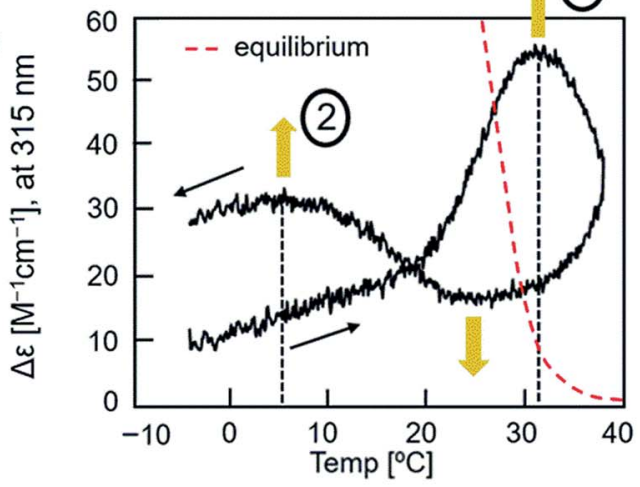

(c)

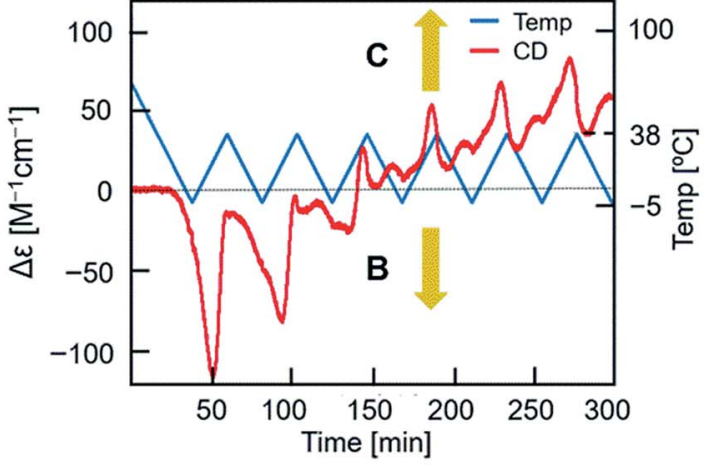

(d)

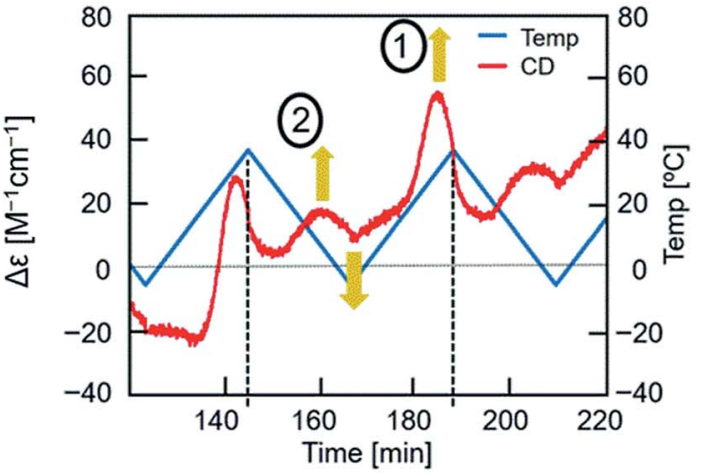

Fig. 4 Chemical $C D$ oscillation phenomenon of $(P)-1 /(M)-3(1: 1)$ in toluene (total $0.25 \mathrm{mM}$ ) at a heating/cooling rate of $2.0 \mathrm{~K} \mathrm{~min}^{-1}$. The temperature was decreased from $70{ }^{\circ} \mathrm{C}$ to $-5^{\circ} \mathrm{C}$, and then oscillated 6 times between $-5{ }^{\circ} \mathrm{C}$ and $38^{\circ} \mathrm{C}$. The results are shown (a) in the $\Delta \varepsilon$ $(315 \mathrm{~nm}) /$ temperature profiles, (b) in the fourth heating and cooling cycle, (c) in $\Delta \varepsilon$ (315 nm)/time profiles and (d) in the fourth heating and cooling cycle. Two $\Delta \varepsilon$ maxima, 1 and 2, are shown in (b and d). Equilibrium curves are shown by red dashed lines in ( $a$ and b), which were obtained from Fig. S18.† Orange arrows in $(b-d)$ indicate self-catalytic amplifications. (a)

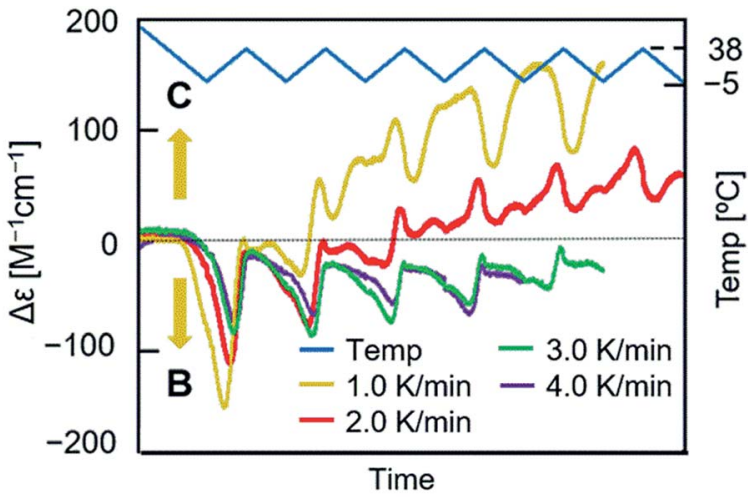

(b)

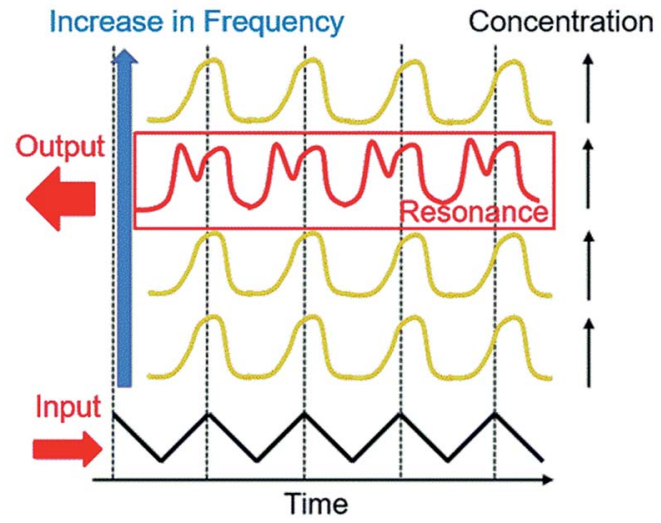

Fig. 5 Chemical resonance phenomenon of $(P)-1 /(M)-3(1: 1)$ in toluene (total $0.25 \mathrm{mM}$ ) at heating and cooling rates of $1.0 \mathrm{~K} \mathrm{~min}^{-1}$ (yellow line), $2.0 \mathrm{~K} \mathrm{~min}^{-1}$ (red line), $3.0 \mathrm{~K} \mathrm{~min}^{-1}$ (green line), and 4.0 $\mathrm{K} \mathrm{min}^{-1}$ (purple line). Experimental data are shown in Fig. S10 to S13. $\dagger$ To compare different temperature change rate experiments, time was normalized by temperature oscillation (blue line). The results are shown (a) in $\Delta \varepsilon(315 \mathrm{~nm}) /$ time profiles and (b) in an explanation. Orange arrows in (a) indicate self-catalytic amplifications.

chemical CD oscillation occurs only at a specific temperature oscillation rate (Fig. 5b). Such a resonance phenomenon is common in electronics, whereas resonance in a chemical reaction subjected to a temperature oscillation as shown in this study is notable. The effect of the temperature oscillation range was examined, and chemical CD oscillation occurred between $-5{ }^{\circ} \mathrm{C}$ and $30 / 45^{\circ} \mathrm{C}$ (Fig. S14-S17†).

\section{Determination of equilibrium states}

Equilibrium states (red dashed lines in Fig. $4 \mathrm{a}$ and $\mathrm{b}$ ) were determined at different temperatures of $(P)-\mathbf{1} /(M)-\mathbf{3}(1: 1)$ in toluene (total $0.25 \mathrm{mM}$ ) for $\Delta \varepsilon$ at $315 \mathrm{~nm}$ employing constanttemperature (isothermal) procedures. A cooling experiment was conducted for $2 \mathrm{~A}$ (Fig. S18 ${ }^{\dagger}$ ). Solutions were heated to $70^{\circ} \mathrm{C}$ to form $2 \mathrm{~A}$, cooled to $60,50,40$, and $30^{\circ} \mathrm{C}$, and allowed to settle for $30 \mathrm{~min}$. Then, the $\Delta \varepsilon$ values were determined to be between +5 and $0 \mathrm{~cm}^{-1} \mathrm{M}^{-1}$. Another experiment was conducted by cooling to $25{ }^{\circ} \mathrm{C}$ and settling for 10 days, which provided $\Delta \varepsilon$ $+67 \mathrm{~cm}^{-1} \mathrm{M}^{-1}$. A heating experiment was conducted for $\mathbf{C}$ (Fig. S18 and S19†). Solutions were heated to $70{ }^{\circ} \mathrm{C}$, cooled to $5{ }^{\circ} \mathrm{C}$, and allowed to settle for $4-8$ days, which resulted in $\Delta \varepsilon$ 
$+195 \mathrm{~cm}^{-1} \mathrm{M}^{-1}$ indicating the formation of $\mathbf{C}$. Then, the solutions were heated to 20,25 , and $30{ }^{\circ} \mathrm{C}$, and allowed to settle for 3-8 days, during which $\Delta \varepsilon$ decreased to $+150,+70$, and $+16 \mathrm{~cm}^{-1}$ $\mathbf{M}^{-1}$, respectively. Then, the isothermal procedures at $30{ }^{\circ} \mathrm{C}$ employing cooling and heating experiments indicated that the equilibrium state was between 0 and $+16 \mathrm{~cm}^{-1} \mathrm{M}^{-1}$; isothermal experiments at $25{ }^{\circ} \mathrm{C}$ indicated that the equilibrium state was between +67 and $+70 \mathrm{~cm}^{-1} \mathrm{M}^{-1}$. An equilibrium curve was drawn between 20 and $50{ }^{\circ} \mathrm{C}$ in the $\Delta \varepsilon$ /temperature profile (Fig. 4a and b). Notably, the curves obtained for experiments on temperature oscillation significantly and repeatedly crossed the equilibrium curve, which is referred to as equilibrium crossing. ${ }^{21}$

\section{Domain analysis}

An explanation of the chemical CD oscillation phenomenon is provided, which is caused by the competition between selfcatalytic $2 \mathbf{A}+\mathbf{B}$-to-2 $\mathbf{B}$ and $2 \mathbf{A}+\mathbf{C}$-to-2C reactions (Fig. $1 \mathrm{c}$ and $6 a)$. At an oscillation rate of $2.0 \mathrm{~K} \mathrm{~min}^{-1}$, the competition between the two self-catalytic reactions resulted in two $\Delta \varepsilon$ maxima, 1 and 2, and a minimum in a single heating and cooling cycle (Fig. $4 \mathrm{~b}$ and $\mathrm{d}$ ). For the large $\Delta \varepsilon$ maximum 1 during heating, the self-catalytic $2 \mathbf{A}+\mathbf{C}$-to-2C reaction predominates, and $\Delta \varepsilon$ increases. For the small maximum 2 during cooling, the same reaction predominates. For the large minimum during cooling, the self-catalytic $2 \mathbf{A}+\mathbf{B}$-to- $2 \mathbf{B}$
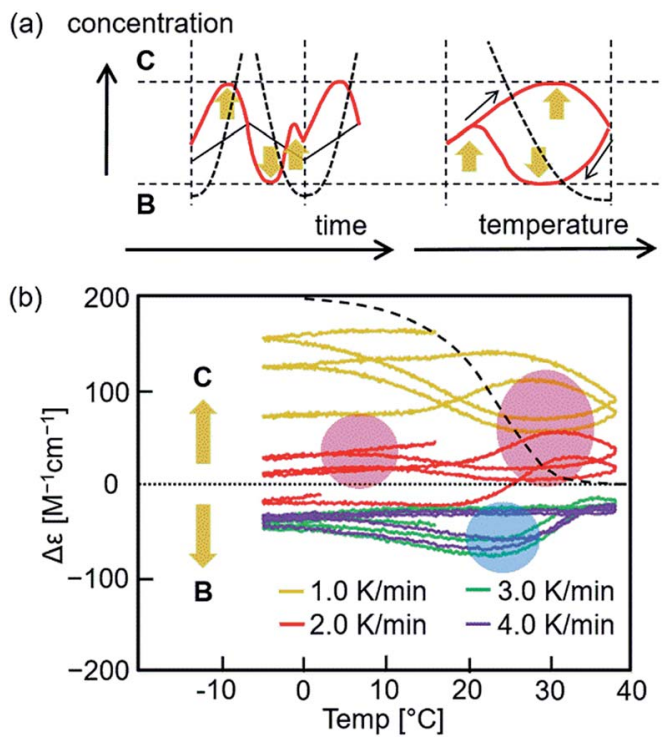

Fig. 6 (a) An explanation of experimental results of chemical $C D$ oscillation phenomenon, in which competitive self-catalytic amplification forms B and C, which is shown by concentration/time and concentration/temperature profiles. The figure shows concentration oscillation (red lines), temperature oscillation (black lines), and equilibrium curves (black dashed curves). Orange arrows indicate selfcatalytic amplifications. (b) Domain analysis of $(P)-1 /(M)-3(1: 1)$ in toluene (total $0.25 \mathrm{mM}$ ) at different temperature oscillation rates of 1.0, 2.0, 3.0, and $4.0 \mathrm{~K} \mathrm{~min}^{-1}$, which is shown in $\Delta \varepsilon$ /temperature profiles. Domains are shown, in which either the self-catalytic $2 \mathrm{~A}+\mathrm{B}$-to-2B (red shade) or the $2 \mathrm{~A}+\mathrm{C}$-to-2C (blue shade) reaction predominates. The equilibrium curve is also shown (black dashed lines). reaction predominates, and $\Delta \varepsilon$ decreases. The competition between the two amplified chemical reactions induces sharp switching between the concentrations of $\mathbf{B}$ and $\mathbf{C}$. An explanation for the chemical $\mathrm{CD}$ oscillation phenomenon is also provided by orange arrows in Fig. 6a.

The rate of a self-catalytic reaction is then highly dependent on the temperature and concentration of products or the catalysts $\mathbf{B}$ and $\mathbf{C}$. Domains can be shown in $\Delta \varepsilon$ /temperature profiles, where $\mathbf{B}$ and $\mathbf{C}$ formation reactions predominate. Experiments with different rates (Fig. 5a) were overlaid (Fig. 6b and $\mathbf{S} 20^{\dagger}$ ), and $\mathbf{B}$ and $\mathbf{C}$ formation domains are shown as indicated by the downward inflation (blue shade) and upward inflation (red shade) of $\Delta \varepsilon$, respectively. The formation of $\mathbf{B}$ is accelerated at a domain centered at $20{ }^{\circ} \mathrm{C}$ with $\Delta \varepsilon-100 \mathrm{~cm}^{-1}$ $\mathbf{M}^{-1}$, and the formation of $\mathbf{C}$ is accelerated at domains centered at 30 and $5{ }^{\circ} \mathrm{C}$ with $\Delta \varepsilon+100 \mathrm{~cm}^{-1} \mathrm{M}^{-1}$. This result is consistent with the two $\Delta \varepsilon$ maxima, 1 and 2 , and one minimum observed in the $\Delta \varepsilon$ /temperature profiles (Fig. $4 \mathrm{~b}, \mathrm{~d}$, and $6 \mathrm{a}$ ).

With regard to the chemical resonance phenomenon, at a low temperature oscillation rate of $1.0 \mathrm{~K} \mathrm{~min}^{-1}$, the selfcatalytic $2 \mathbf{A}+\mathbf{C}$-to- $2 \mathbf{C}$ reaction predominates, and $\Delta \varepsilon$ increases with the temperature oscillation rate; at a high temperature oscillation rate of 3.0 and $4.0 \mathrm{~K} \mathrm{~min}^{-1}$, the self-catalytic $2 \mathbf{A}+\mathbf{B}$ to- $2 \mathbf{B}$ reaction predominates, and $\Delta \varepsilon$ does not change significantly with the temperature oscillation rate; at an intermediate oscillation rate of $2.0 \mathrm{~K} \mathrm{~min}{ }^{-1}$, both self-catalytic reactions compete.

It was also noted that changes in concentrations occur significantly on both sides of the equilibrium curve, which is the lowest valley in a potential surface formed in concentration/ temperature profiles (Fig. 6b). These changes depend on the rate of temperature oscillation, and equilibrium crossing occurs at relatively low rates of 1.0 and $2.0 \mathrm{~K} \mathrm{~min}^{-1}$. In contrast at higher rates of 3.0 and $4.0 \mathrm{~K} \mathrm{~min}^{-1}$, changes in concentrations occur in the domains far from the equilibrium curve. The nature of competitive systems involving self-catalytic amplification chemical reactions is noted, which occurs during crossing of chemical equilibrium.

\section{Conclusions}

To summarize, a pseudoenantiomeric mixture of aminomethylenehelicene oligomers $(P)$-tetramer $(P)$-1 and $(M)$-hexamer $(M)$-3 exhibits chemical CD oscillation and chemical resonance phenomena, which are derived from molecules dispersed in solution without forming higher aggregates. These notable chemical phenomena are derived from the competition between two self-catalytic $2 \mathbf{A}+\mathbf{C}$-to- $2 \mathbf{C}$ and $2 \mathbf{A}+\mathbf{B}$-to- $2 \mathbf{B}$ reactions that provide different products, $\mathbf{C}$ and $\mathbf{B}$, respectively, in an amplified manner. The phenomenon of equilibrium crossing is also observed.

\section{Conflicts of interest}

There are no conflicts to declare. 


\section{Acknowledgements}

This work was financially supported by the Grants-in-Aid for Scientific Research (No. 17H03050 and 17H08203) from the Japan Society for the Promotion of Science (JSPS). T. S. thanks the JSPS for a Fellowship for Young Japanese Scientists (No. 18J10706). N. S. thanks the Sumitomo Foundation for financial support.

\section{Notes and references}

1 P. Atkins and J. de Paula, Physical Chemistry, Oxford University Press, Oxford, 10th edn, 2014.

2 P. L. Houston, Chemical Kinetics and Reaction Dynamics, Dover Publications, Inc., New York, 2006.

3 R. A. van Santen and J. W. Niemantsverdriet, Chemical Kinetics and Catalysis, Plenum Press, New York, 1995.

4 R. P. Feynman, R. B. Leighton, and M. Sands, The Feynman Lectures on Physics, Addison-Wesley Publishing Co., Inc., MA, 1965, vol. 2.

5 F. S. Crawford Jr, Berkeley Physics Course, Education Development Center, Inc., MA, 1971, vol. 3.

6 N. Schinor, W. Hohmann, M. Kraus, J. Müller and F. W. Schneider, Phys. Chem. Chem. Phys., 1999, 1, 827-832.

7 K. Otawara and L. T. Fan, J. Phys. Chem. A, 1997, 101, 96789680.

8 J. G. Lazar and J. Ross, Science, 1990, 247, 189-192.

9 J. M. Douglas and D. W. T. Rippin, Chem. Eng. Sci., 1966, 21, 305-315.
10 M. S. Samples, Y.-F. Hung and J. Ross, J. Phys. Chem., 1992, 96, 7338-7342.

11 For example of complex phenomena in aggregated states. P. Mineo, V. Villari, E. Scamporrino and N. Micali, J. Phys. Chem. B, 2015, 119, 12345-12353.

12 M. Wolffs, S. J. George, Z. Tomovic, S. C. J. Meskers, A. P. H. J. Schenning and E. W. Meijer, Angew. Chem., Int. Ed., 2007, 46, 8203-8205.

13 Y. Demirel, Non-Equilibrium Thermodynamics: Transport and Rate Processes in Physical, Chemical and Biological Systems, Elsevier, Amsterdam, 2nd edn, 2007.

14 I. R. Epstein and J. A. Pojman, An Introduction to Nonlinear Chemical Dynamics, Oxford University Press, New York, 1998.

15 K. S. Scott, Chemical Chaos, Oxford University Press, Oxford, 1991.

$16 \mathrm{~S}$. R. de Groot and P. Mazur, Non-Equilibrium Thermodynamics, Dover Publication, New York, 1984.

17 M. Shigeno, Y. Kushida and M. Yamaguchi, J. Am. Chem. Soc., 2014, 136, 7972-7980.

18 Y. Kushida, T. Sawato, M. Shigeno, N. Saito and M. Yamaguchi, Chem.-Eur. J., 2017, 23, 327-333.

19 Y. Kushida, T. Sawato, N. Saito, M. Shigeno, H. Satozono and M. Yamaguchi, ChemPhysChem, 2016, 17, 3283-3288.

20 Y. Kushida, N. Saito, M. Shigeno and M. Yamaguchi, Chem. Sci., 2017, 8, 1414-1421.

21 M. Miyagawa, A. Yagi, M. Shigeno and M. Yamaguchi, Chem. Commun., 2014, 50, 14447-14450. 